\title{
Influence of Measurement Procedure on the Korean Matrix Sentence-in-Noise Intelligibility for Normal-Hearing Listeners
}

\author{
Kyung Hyun $\operatorname{Kim}^{1}$ (D) and Jae Hee Lee ${ }^{1,2}$ iD \\ ${ }^{1}$ Department of Audiology and Speech-Language Pathology, Hallym University of Graduate Studies, Seoul; and \\ ${ }^{2} H U G S$ Center for Hearing and Speech Research, Seoul, Korea
}

\author{
측정 절차가 건청인의 한국어 Matrix 소음하 문장인지에 미치는 영향 \\ 김경현 ${ }^{1} \cdot$ 이재희 ${ }^{1,2}$ \\ 한림국제대학원대학교 청각언어치료학과, ${ }^{1}$ 청각언어연구소 ${ }^{2}$
}

\author{
Received October 8, 2019 \\ Revised April 29, 2020 \\ Accepted May 7, 2020 \\ Address for correspondence \\ Jae Hee Lee, PhD \\ Department of Audiology and \\ Speech-Language Pathology, \\ HUGS Center for Hearing \\ and Speech Research, \\ Hallym University \\ of Graduate Studies, \\ 427 Yeoksam-ro, Gangnam-gu, \\ Seoul 06198, Korea \\ Tel $+82-2-2051-2942$ \\ Fax $+82-2-3453-7833$ \\ E-mail leejaehee@hallym.ac.kr
}

Background and Objectives A Korean Matrix Sentence Test is one of the adaptive tests used to evaluate speech intelligibility in noise. The present study aimed to investigate the influence of measurement procedure (presentation level and mode) on the Korean matrix sentence-in-noise intelligibility of normal-hearing listeners.

Subjects and Method Twenty-seven normal-hearing adults participated in the study. The speech reception threshold (SRT) was determined using a software-based adaptive procedure, which converges on the signal-to-noise ratio (SNR), corresponding to $50 \%$ intelligibility. The speech or speech-shaped noise was given at three presentation levels based on the previous categorical loudness judgments (between soft and medium: $55 \mathrm{~dB}$ SPL, medium: $65 \mathrm{~dB}$ SPL, and loud level: $80 \mathrm{~dB}$ SPL). The effect of the presentation mode was explored by fixing either the sentence level or noise level, while the noise or sentence level was adaptively adjusted according to the subject's response.

Results The presentation level significantly affected the SRTs, whereas the SRTs did not depend on the presentation mode. The sentence-in-noise intelligibility was similar between 55 and $65 \mathrm{~dB}$ SPL, yet the sentence-in-noise intelligibility significantly decreased at $80 \mathrm{~dB}$ SPL regardless of the presentation mode. Correlation analyses showed moderate to high positive correlations among the results of two presentation modes.

Conclusion A presentation level of 55 or $65 \mathrm{~dB}$ SPL yielded comparable adaptive measurement results for normal-hearing subjects, yet the sentence-in-nose intelligibility became worse at $80 \mathrm{~dB}$ SPL. Clinicians should be careful with the influence of the presentation level when identifying speech-in-noise intelligibility.

Korean J Otorhinolaryngol-Head Neck Surg 2021;64(1):7-12

Key Words Korean Matrix Sentence Test · Measurement procedure ·

Sound-field speech audiometry $\cdot$ Speech in noise intelligibility.

\section{서 론 \\ 접하며, 이러한 배경 소음은 어음인지 및 의사소통 능력 등을 저하시킬 수 있다. ${ }^{1-5)}$ 임상 현장에서 대상자의 의사소통 능력 우리는 일상생활 속에서 소음이 포함된 듣기 환경을 자주 을 예측하기 위해 주로 조용한 상황에서의 단어인지도를 측}

This is an Open Access article distributed under the terms of the Creative Commons Attribution Non-Commercial License (https://creativecommons.org/licenses/by-nc/4.0) which permits unrestricted non-commercial use, distribution, and reproduction in any medium, provided the original work is properly cited. 
정하는데, 이와 같이 소음 없이 측정한 어음청각검사 결과는 난청인의 소음 상황 속 의사소통 능력 및 보청기 혜택을 신 뢰도 있게 예측하지 못한다. ${ }^{6}$

소음 상황에서 보청기가 얼마나 혜택을 주는지 정량화하 기 위해 라우드스피커를 통해 문장을 제시하고 음장 소음하 문장인지검사(sound-field sentence-in-noise recognition test)를 시행할 수 있다. 국외의 경우 Hearing in Noise Test (HINT), ${ }^{7)}$ QuickSIN ${ }^{\mathrm{TM}}$, ${ }^{8)}$ Matrix ${ }^{9)}$ 소음하 문장인지검사 도구 를 개발하여 진단 및 연구의 목적으로 사용하고 있다. 위의 검사 도구들은 모두 대상자의 반응에 따라 신호대소음비(signal-to-noise ratio, SNR)를 변동하여 50\% 인지도에 해당하 는 SNR을 찾는 변동형(adaptive) 검사 도구이다. 그러나 각 검사 도구마다 사용하는 제시 레벨, 제시 방법, 결과 산출 방 법 등이 서로 다르다. ${ }^{10)}$ 예를 들어, HINT 검사의 경우 보통 대상자의 정면 $\left(0^{\circ}\right)$ 스피커에서 목표 문장을 제시하고 대상자 의 정면 $\left(0^{\circ}\right)$, 오른쪽 $\left(90^{\circ}\right)$, 왼쪽 $\left(-90^{\circ}\right)$ 방향 중 하나에서 소음 을 제시하며, 소음의 레벨은 $65 \mathrm{dBA}$ 에서 고정한 채 문장의 레벨을 변동하여 $50 \%$ 의 소음하 문장인지를 보이는 SNR을 찾는다. QuickSIN ${ }^{\mathrm{TM}}$ 검사의 경우 $\mathrm{HINT}$ 검사와 반대로 문 장 레벨을 고정한 채 소음 레벨을 변동하여 SNR을 찾는다. Matrix 소음하 문장인지검사 도구는 현재 15 개의 언어로 개 발되어 있고, 각 언어의 Matrix 검사 도구 개발 시 단어 및 문장 구성부터 녹음 및 소음 제작, 문장 최적화, 신뢰도 및 타당도 분석을 위한 절차 등을 최대한 동일하게 하여 서로 다른 언어임에도 결과 비교가 가능하다는 특징을 가진다. ${ }^{11)}$ Matrix 문장인지검사 시 HINT 검사처럼 고가의 검사 세팅이 아닌 일반적으로 사용하는 음장 검사용 라우드스피커를 통 해 음장 소음하 문장인지검사가 가능하고, 목적에 따라 문장 과 소음의 위치를 분리하여 검사를 시행할 수 있다. 보통 소 음 레벨을 $65 \mathrm{~dB} \mathrm{SPL}$ 에 고정한 채 Matrix 문장인지검사를 진행하도록 하지만 소음이 아닌 문장 레벨을 고정한 채 검사 를 진행할 수 있고, $65 \mathrm{~dB} \mathrm{SPL뿐} \mathrm{아니라} \mathrm{50,} 80 \mathrm{~dB} \mathrm{SPL}$ 의 제시 레벨도 선택할 수 있어 평균 대화음 레벨인 $65 \mathrm{~dB} \mathrm{SPL}$ 에서 어음을 듣기 어려운 고도 이상의 난청인에게 음장 소음 하 어음청각검사를 시행할 수 있다는 장점이 있다.

임상 현장에서 검사자가 서로 다른 검사 방법 및 절차를 이용할 경우 검사 결과가 상이할 수 있으므로 이에 대한 검 증이 필수적이다. 선행 연구에서 건청 성인 10 명을 대상으로 독일어 버전 Matrix 문장인지검사를 통해 제시 레벨과 제시 방법에 따른 효과를 평가한 결과 두 변수 모두 소음하 문장 인지도에 유의한 영향을 주지 않았다. ${ }^{12)}$ 그러나 이 연구에 참 여한 대상자 수가 적고, 문장과 소음의 레벨을 모두 변동한 것이 아니므로 제시 방법별로 제시 레벨에 따른 효과를 알아
볼 필요가 있다. 따라서 본 연구에서는 변동형 절차로 음장 어음청각검사가 가능한 한국어 Matrix 문장인지검사 도구를 이용하여 제시 레벨과 제시 방법이 건청 성인의 Matrix 소음 하 문장인지도에 미치는 영향을 확인하고, 결과 간 상관성을 확인하였다. 제시 레벨 선정 시 선행 연구 ${ }^{13}$ 결과를 고려하여 작은 음량과 보통 음량 사이(between soft and medium)에 해당하는 $55 \mathrm{~dB} \mathrm{SPL}$, 보통 음량(medium)에 해당하는 $65 \mathrm{~dB}$ $\mathrm{SPL}$, 큰 음량(loud)에 가까운 $80 \mathrm{~dB}$ SPL에서 문장 혹은 소 음을 제시하였다.

\section{대상 및 방법}

\section{대 상}

본 연구에는 정상 청력을 가진 성인 27 명(남성 14 명, 여성 13 명)이 참여하였다(평균 30.63세, 연령 범위 25 39세). 순음 청력검사와 어음청각검사 결과(GSI 61 청력검사기; GrasonStadler, Eden Prairie, MN, USA), 양측 귀 모두 250 8000 $\mathrm{Hz}$ 이내 옥타브 단위 주파수에서 $20 \mathrm{~dB} \mathrm{HL}$ 미만의 순음청 력역치를 보였고, 조용한 상황에서 대상자의 쾌적 레벨에서 단어를 제시한 경우 $100 \%$ 의 단어인지도를 보였다. 임피던스 청력검사기기(r25C; Resonance, Gazzaniga, Italy)를 이용 하여 양 귀의 고막운동도 검사를 실시한 결과, 모두 A형 고막 운동성을 보였다. 대상자 모두 이과 및 신경학적 병력이 없었 으며, 연구 참여 전 연구의 목적 및 절차에 대한 설명을 듣고 연구 참여에 동의하였다(IRB: HUGSAUD256198).

\section{연구 절차}

본 연구에서는 목록 간 동질성과 신뢰도 등이 검증된 한 국어 Matrix 문장 음원과 어음스펙트럼을 가진 비유동성 소 음을 사용하였다. ${ }^{14)}$ 본 연구에서 사용한 Matrix 문장은 $10 \times 5$ 행렬(matrix)에 포함된 50개의 단어 중 5 개의 단어(주어 1 개, 형용사 1 개, 명사 1 개, 수사 1 개, 동사 1개)의 조합으로 각 문 장을 구성한다. Matrix 문장인지검사에서는 Oldenburg Measurement Applications(OMA) 소프트웨어를 이용하여 대상 자의 반응에 따라 자동으로 문장 혹은 소음의 레벨을 조절 한다. 검사 시 대상자가 각 문장을 듣고 문장 내 단어를 따라 말하면 대상자의 반응에 따라 최대우도측정(maximum likelihood estimator) ${ }^{15,16}$ 에 근거하여 SNR 단위를 변화시키며 $\mathrm{SNR}$ 을 조절한다. 즉 최대우도측정 절차에서는 직전 자극음 들에 대한 반응들에 기준하여 그 다음 자극음의 강도를 변 동 조절한다. $\mathrm{OMA}$ 소프트웨어에서는 아래의 로지스틱 함수 Eq. [1]을 통해 $50 \%$ 소음하 문장인지도에 해당하는 SNR과 $50 \%$ 접점 기울기를 구하여 speech recognition threshold 
(SRT)를 확인한다.

$$
\mathrm{p}(\mathrm{L}, \mathrm{SRT}, \mathrm{s})=\frac{1}{1+\mathrm{e}^{4 \mathrm{~S}(\mathrm{SRT} T \mathrm{~L})}}
$$

본 연구에서는 제시 레벨과 제시 방법(소음 혹은 문장 레 벨을 고정)에 따른 소음하 문장인지도를 측정하기 위해 소음 레벨을 $55,65,80 \mathrm{~dB}$ SPL에 고정한 채 문장의 레벨을 변동 하여 SRT를 구하거나, 반대로 문장 레벨을 $55,65,80 \mathrm{~dB} \mathrm{SPL}$ 으로 고정한 채 소음 레벨을 변동하여 $50 \%$ 인지도에 해당하 는 SRT를 구하였다. $55,65,80 \mathrm{~dB}$ SPL의 레벨에서 소음이나 문장을 제시한 근거는 선행 연구 결과 건청인이 $55 \mathrm{~dB} \mathrm{SPL}$ 의 소음을 작은 음량과 보통 음량의 사이의 소리로, $65 \mathrm{~dB} \mathrm{SPL}$ 의 소음은 보통 음량으로, $85 \mathrm{~dB} \mathrm{SPL}$ 의 소음은 큰 소리로 음량범주화(categorical loudness scaling)하였기 때문이다. ${ }^{13)}$

본 연구에서는 불쾌 음량에서의 문장 제시를 피하기 위해 범선행 연구 ${ }^{12}$ 와 마찬가지로 $85 \mathrm{~dB}$ SPL이 아닌 $80 \mathrm{~dB} \mathrm{SPL}$ 에서 문장을 제시하였다.

본 연구의 실험은 국제표준에서 권고하는 소음허용수준 (ISO 8253-3:2012)을 만족하는 방음실에서 진행하였다. 검사 시 free-field equalized 헤드폰(HDA200; Sennheiser Electronics GmbH \& Co. KG, Wedemark-Wennebostel, Germany), Fireface UCX 디지털-아날로그 변환기(RME; Haimhausen, Germany), 노트북(gram; LG electronics, Seoul, Korea)을 사용하였다.

선행 연구자들은 Matrix 문장인지검사 시 적어도 2개의 연습 목록을 통해 문장을 듣고 따라 말하기, 소음 혹은 문장 이 변동하는 상황에서 문장 인지하기 등에 대한 연습이 되어 야 실제 실험 결과가 안정적으로 관찰된다고 보고한 바 있 다. ${ }^{11,12)}$ 따라서 본 연구에서도 연습 문장 목록을 제시하여 훈 련 효과(training effect)를 확인하였다. 실제 실험에서 제시 레벨과 제시 방법에 따라 반복적으로 소음하 문장인지도를 측정하였으므로 순서에 따른 이월(carryover) 효과를 고려 하여 라틴스퀘어 실험 설계에 따라 검사를 진행하였다.

\section{통계 분석}

수집된 결과는 SPSS 25.0 version(IBM Corp., Armonk, $\mathrm{NY}, \mathrm{USA}$ )을 이용하여 분석하였고, 유의 수준은 0.05 를 기준 으로 통계적 유의성을 확인하였다. Shapiro-Wilk 정규성 검 정을 시행하여 데이터가 정규분포를 따르는지 여부를 확인하 였고, 정규성 만족이 충족된 경우 모수 검정을 시행하였다. 연습 절차를 통한 결과와 실제 실험 결과 간 훈련 효과가 있 었는지 검증하기 위해 반복측정된 일원분산분석을 시행하였
다. 제시 레벨과 제시 방법(그룹 내 독립변수)이 소음하 문장 인지도에 미치는 영향을 확인하기 위해 반복 측정된 이원분 산분석을 시행하였으며, 구형성 가정이 만족되지 않았을 경 우 Greenhouse-Geisser의 수정된 검정 통계량을 보고하였 다. 유의한 주효과로 다중비교가 필요한 경우 1 종 오류의 증 가를 조정하기 위해서 ${ }^{17)}$ Bonferroni correction method를 적용하였다. 피어슨 상관분석을 통해 검사 결과 간 상관성을 분석하였고, 피어슨 상관계수가 0.3 0.5면 낮은 상관성, 0.5 0.7면 보통의 상관성, 0.7 0.9면 높은 상관성, 0.9 이상이면 매우 높은 상관성을 가진다고 해석하였다.

\section{결 과}

\section{훈련 효과}

영어, 중국어, 독일어 등의 Matrix 소음하 문장인지 측정 결과, 연습 절차와 실제 실험 결과 간 약 $0.7 \sim 1.5 \mathrm{~dB}$ 의 SRT 차이가 있으므로 최소한 두 개의 Matrix 문장 목록을 이용 하여 연습을 할 것을 권장하였다. ${ }^{11,12,18)}$ 선행 연구와의 비교를 위해 본 연구에서도 동질성이 입증된 네 개의 목록을 통해 반복적으로 소음하 문장인지도를 측정하여 몇 번째 목록부 터 훈련 효과의 영향을 받지 않는지 확인하였다.

Fig. 1의 SRT를 통해 알 수 있듯이, 목록 제시 순서대로 평 균 $\mathrm{SRT}$ 가 $-6.46 \mathrm{~dB} \mathrm{SNR} \pm 1.04,-7.49 \mathrm{~dB} \mathrm{SNR} \pm 0.93$, $-8.12 \mathrm{~dB}$ SNR $\pm 0.64,-8.27 \mathrm{~dB}$ SNR \pm 0.78 (중앙값: -6.50 , $-7.50,-8.00,-8.20 \mathrm{~dB} \mathrm{SNR})$ 으로 목록 간 SRT가 유의하게 달랐다 $[\mathrm{F}(3,78)=55.05, p<0.05]$. 다중비교 결과, 첫번째로 시 행한 검사 결과가 두번째, 세번째, 네번째 시행한 검사 결과 보다 유의하게 더 높았다(나빴다). 두번째 시행한 검사 결과 역시 세번째, 네번째 시행한 검사 결과보다 유의하게 더 높았

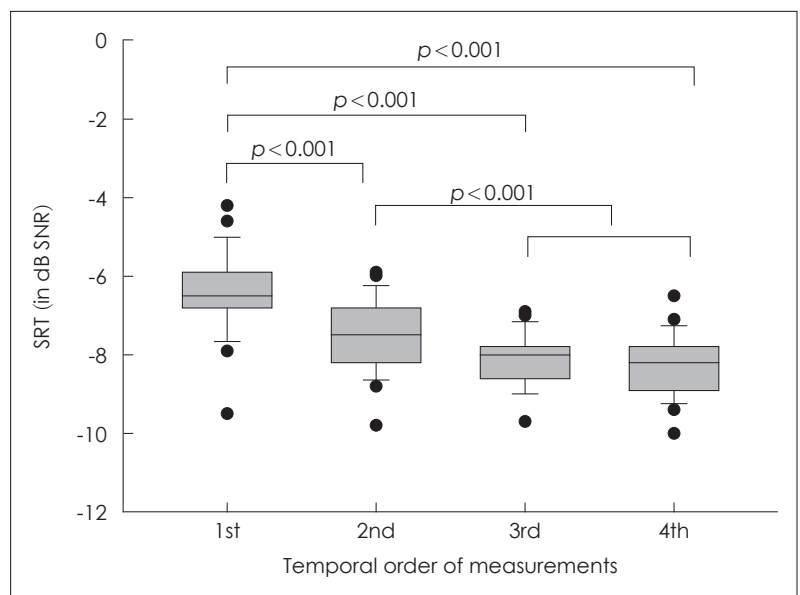

Fig. 1. Boxplots of SRTs as a function of temporal order of measurements (boxes: the 25th and 75th percentiles, solid lines: median value, error bars: the 10th and 90th percentiles, circles: outliers). SRT: speech recognition threshold, SNR: signal-to-noise ratio. 

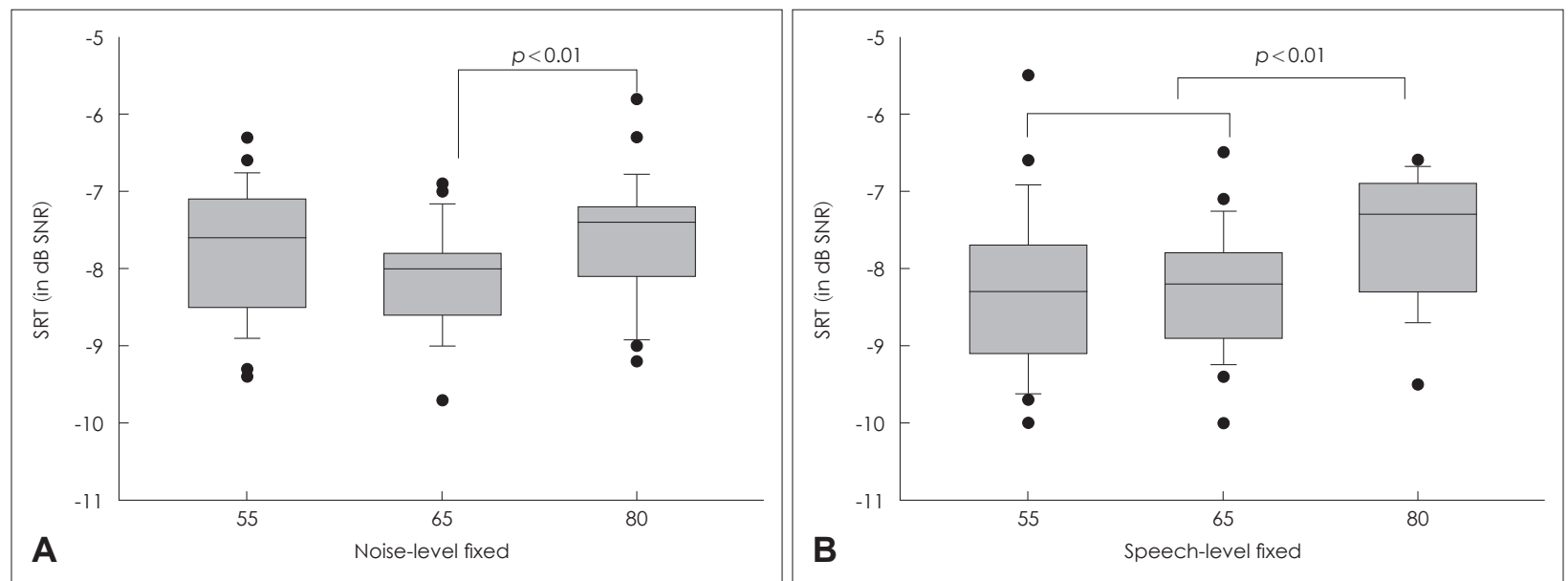

Fig. 2. Boxplots of SRTs when noise or speech level was fixed (boxes: the 25th and 75th percentiles, solid lines: median value, error bars: the 10th and 90th percentiles, circles: outliers). SRT: speech recognition threshold, SNR: signal-to-noise ratio.

다(나빴다). 세번째와 네번째 제시한 목록 간 결과는 유의하 게 다르지 않았다. 즉, 선행 연구와 유사하게 두 개의 문장 목록을 통해 연습 과정을 거칠 경우 그 이후(세번째)부터 측 정하는 소음하 문장인지도가 유의하게 변화하지 않고 비교 적 안정적임을 확인하였다.

\section{제시 레벨과 제시 방법에 따른 소음하 문장인지도}

Fig. 2는 제시 레벨(55, 65, $80 \mathrm{~dB}$ SPL)과 제시 방법(소음 레벨을 고정 vs. 문장 레벨을 고정)에 따른 평균 SRT를 보여 준다. 소음의 레벨을 $55,65,80 \mathrm{~dB} \mathrm{SPL}$ 에서 고정한 채 문장 의 레벨을 변동하여 $50 \%$ 인지도에 해당하는 SRT를 구한 결 과, 소음의 레벨 순서대로 평균 SRT는 $-7.79 \mathrm{~dB}$ SNR \pm 0.81 , $-8.13 \mathrm{~dB}$ SNR $\pm 0.64,-7.57 \mathrm{~dB}$ SNR \pm 0.77 이었다(중앙값: $-7.60,-8.00,-7.40 \mathrm{~dB}$ SNR). 소음이 아닌 문장의 레벨을 55 , $65,80 \mathrm{~dB}$ SPL에 고정한 채 소음의 레벨을 변동하여 소음하 문장인지도를 측정한 결과 평균 SRT가 $-8.26 \mathrm{~dB} \mathrm{SNR} \pm 1.04$, $-8.26 \mathrm{~dB}$ SNR $\pm 0.78,-7.60 \mathrm{~dB}$ SNR \pm 0.81 이었다(중앙값: $-8.30,-8.20,-7.30 \mathrm{~dB}$ SNR).

반복 측정된 이원분산분석을 시행한 결과, 제시 레벨이 미 치는 주효과는 유의하였으나 $[\mathrm{F}(1.57,40.70)=14.23, p<0.05]$, 제시 방법에 따른 주효과와 제시 레벨과 제시 방법 간 이원 상호작용은 유의하지 않았다. 각 제시 방법에 따른 결과에서 제시 레벨 간 차이를 확인하기 위해 다중 비교를 시행한 결과, 소음 레벨을 고정하고 문장의 레벨을 변동한 경우 $80 \mathrm{~dB} \mathrm{SPL}$ 에서 측정한 평균 결과가 $65 \mathrm{~dB} \mathrm{SPL}$ 에서 측정한 결과보다 유 의하게 높았다(나빴다). 문장의 레벨을 고정하고 소음의 레벨 을 변동한 경우 $80 \mathrm{~dB} \mathrm{SPL}$ 에서 측정한 평균 결과가 55 혹은 $65 \mathrm{~dB}$ SPL에서 측정한 결과보다 유의하게 높았고(나뺐다). 두 제시 방법 모두 $55 \mathrm{~dB}$ SPL과 $65 \mathrm{~dB}$ SPL 레벨에서 측정

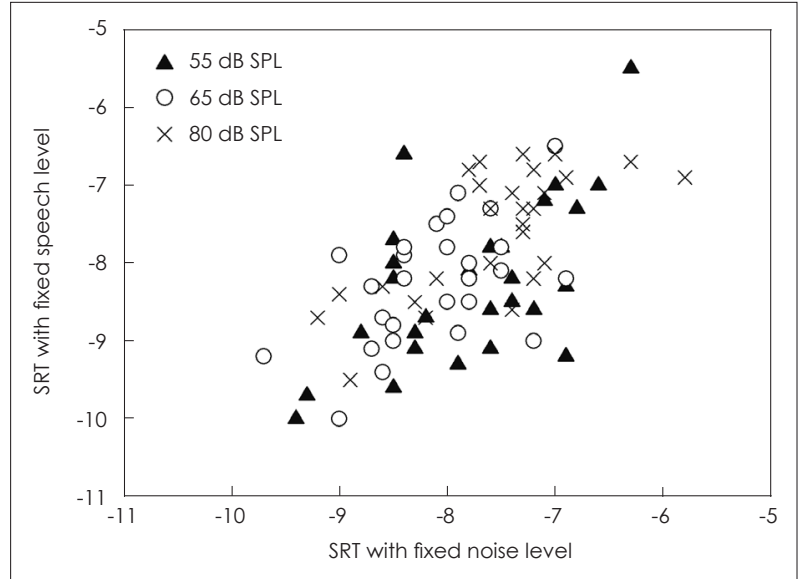

Fig. 3. Scatterplots of individual speech recognition thresholds (SRTs).

한 결과 간 SRT는 유의하게 다르지 않았다.

\section{상관분석 결과}

Fig. 3 은 각 제시 레벨 $(55,65,80 \mathrm{~dB}$ SPL)에서 두 가지 제 시 방법을 통해 측정한 결과 간 상관성을 보여준다. Pearson 상관분석 결과, 소음 레벨 혹은 문장 레벨을 $55 \mathrm{~dB}$ SPL에 고 정하고 구한 SRT 결과 간 피어슨 상관계수는 $\mathrm{r}=0.60(p<0.05)$ 이었고, 소음 레벨 혹은 문장 레벨을 $65 \mathrm{~dB} \mathrm{SPL에} \mathrm{고정하고}$ 구한 측정한 SRT 간 피어슨 상관계수는 $\mathrm{r}=0.52(p<0.05)$ 으로 모두 보통의 양(positive)의 상관 관계를 가짐을 확인하였다. 소음 레벨 혹은 문장 레벨을 $80 \mathrm{~dB} \mathrm{SPL}$ 에 고정하고 구한 측 정한 SRT 간 피어슨 상관계수는 $\mathrm{r}=0.70(p<0.05)$ 으로 높은 양(positive)의 상관 관계를 보였다. 따라서 제시 레벨에 상관 없이 소음 레벨을 고정하고 측정한 소음하 문장인지역치가 낮았던(좋았던) 대상자는 문장 레벨을 고정하였을 때도 소음 하 문장인지역치가 낮았음을 의미한다. 


\section{고 찰}

현대인들은 다양한 일상생활 소음 속에서 자주 의사소통 하므로 조용한 환경에서 측정한 단어인지도만으로 소음이 존재하는 일상생활 속 의사소통 능력을 파악하거나 소음하 듣기 상황에서의 보장구 혜택 정도를 측정하기 어렵다. ${ }^{6,19)}$ 미 국, 영국 등의 의료 선진국에서는 다양한 소음하 문장인지 평가 도구를 개발 및 표준화 후 임상 및 연구의 목적으로 사 용하고 있다. ${ }^{6-9)}$ 그러나 국내의 경우 표준화된 소음하 어음청 각검사 도구가 부족하여 난청인의 소음하 의사소통 능력을 측정하는데 한계가 있다.

Matrix 문장인지검사 도구는 변동형 절차를 적용하는 검 사 도구로 헤드폰 사용 뿐 아니라 라우드스피커를 통한 음장 소음하 문장인지가 가능하다. 현재까지 15 개의 언어로 Matrix 문장인지검사 도구가 개발되었다. ${ }^{9-11)}$ Matrix 문장인지검사 도구는 언어에 상관없이 공통적으로 $10 \times 5$ 행렬에 포함된 단 어 중 5 개의 단어 조합으로 문장을 구성하므로 총 $10^{5}$ 개의 서로 다른 문장이 생성될 수 있어 문장 수가 제한되어 있는 다른 검사 도구에 비해 반복적으로 문장인지를 검사하기 유 용하다.

Matrix 문장인지검사를 시행한 다수의 선행 연구에서 연 습 목록을 제시하지 않고 검사를 진행할 경우 훈련 효과가 실제 결과에 반영될 수 있다고 밝혔다.9,11,15,20-22) 예를 들면 Schlueter 등 22)은 여섯개의 목록을 통해 장단기 훈련 효과가 Matrix 소음하 문장인지에 미치는 영향을 확인한 결과, 첫번 째 문장 목록을 통한 결과에서 두번째 목록에서 얻은 SRT 차이가 가장 컸음(약 $1 \mathrm{~dB})$ 을 밝혀 최소 40 개의 문장(목록 2 개)를 통한 연습 절차가 필요하다고 하였다. 본 연구에서도 네 개의 문장 목록을 통해 훈련 효과를 검증하였다. 분석 결 과, 첫번째보다 두번째 연습 목록을 제시하였을 때 Matrix 소음하 문장인지도가 유의하게 향상하였으나, 세번째 문장 목록부터는 소음하 문장인지도가 유의하게 변화하지 않았다. 따라서 임상에서 한국어 Matrix 소음하 문장인지검사를 진 행할 시 최소 두 개의 목록을 통한 연습 절차를 진행해야 함 을 확인하였다.

Theunissen 등 ${ }^{23}$ 은 소음하 문장인지검사가 소음하 의사소 통 능력을 평가하는데 유용하나 검사 도구마다 서로 다른 검 사 절차를 적용하므로 이에 대해 검사자가 이해하고 결과에 영향을 줄 수 있는 변인들은 최소화해야 한다고 밝혔다. 본 연구에서는 제시 레벨( $55,65,80 \mathrm{~dB} \mathrm{SPL})$ 과 제시 방법(문장 혹은 소음의 레벨을 고정)이 한국어 Matrix 소음하 문장인지 능력에 미치는 영향을 검증하였다. 분석 결과, 건청인의 경우 제시 방법에 상관없이 $55 \mathrm{~dB} \mathrm{SPL}$ 과 $65 \mathrm{~dB}$ SPL에서 소음 혹
은 문장을 제시한 결과는 유의하게 다르지 않았으나, $80 \mathrm{~dB}$ SPL의 제시 레벨을 사용하였을 때 SRT가 평균 0.6 0.7 dB 가량 유의하게 높아졌다(나빠졌다). 제시 레벨이 독일어 $\mathrm{Ma}-$ trix 소음하 문장인지도에 미치는 영향을 확인한 선행 연구의 결과에서 ${ }^{12)} 65 \mathrm{~dB}$ SPL 제시 시보다 $80 \mathrm{~dB}$ SPL 제시 시 SRT 가 약 $0.6 \mathrm{~dB}$ 가량 높았으므로, 제시 레벨에 따른 SRT의 변화 정도를 고려하였을 때 본 연구 결과와 유사하다고 볼 수 있다.

소음없이 조용한 상황에서 고주파수 혹은 저주파수 여과 한 문장을 $75,85,95,105 \mathrm{~dB}$ 에서 제시한 결과,44) 저주파수 정 보만 남아 있는 어음보다 고주파수 정보만 남아 있는 어음일 수록 $85 \mathrm{~dB} \mathrm{SPL}$ 이상의 제시 레벨에서 문장인지도가 더 저 하(약 25\%)되었다고 하였다. 75, 87.5, $100 \mathrm{~dB} \mathrm{SPL}$ 의 제시 레 벨을 이용하여 건청인과 난청인의 소음하 문장인지도를 측정 한 선행 연구 ${ }^{25}$ 에서는 건청인의 경우 75 에서 $87.5 \mathrm{~dB}$ SPL의 제시 레벨 변화로 인해 소음하 문장인지도가 $15 \%$ 이상 감소 하는 롤오버(roll over) 현상을 보였으나 난청인은 동일 레벨 변화에 의해 크게 변화하지 않았다. 문장이 아닌 단어를 통해 69 부터 $99 \mathrm{~dB}$ SPL까지 제시 레벨을 변화하여 건청인과 난 청인의 소음하 단어인지도를 측정한 결과, ${ }^{26)} 69 \mathrm{~dB} \mathrm{SPL}$ 을 초 과한 레벨에서 소음하 단어인지도가 상당히 감소하였다. 제시 레벨의 증가에 따라 동일한 SNR에서의 단어인지도를 분석 한 결과, 단어의 제시 레벨이 증가할수록 소음 레벨이 증가하 게 되므로 이로 인한 부정적인 영향이 더 커져 제시 레벨에 따른 영향이 건청인과 난청인에서 비슷하게 관찰되었음을 밝 혔다. Dubno 등 27) 또한 동일한 SNR을 적용할 경우 소음 레 벨의 증가에 따라 건청 성인의 단어인지도가 저하되었다고 하였고, Hornsby 등 28 은 소음 레벨의 증가(65 100 dB SPL) 로 인해 $0 \mathrm{~dB} \mathrm{SNR}$ 에서 측정한 소음하 자음인지도가 전반적 으로 감소하였으며, 특히 특정 종류의 자음 $(/ \mathrm{d} /, / \mathrm{z} /, / \mathrm{n} /)$ 이 더 영향을 받았다고 하였다. 위의 결과들을 종합해보면 소음 하 어음인지검사시 사용하는 제시 레벨이 소음하 어음인지 능력에 영향을 주므로 검사자는 평가 절차를 결정할 때 주의 할 필요가 있다.

요약하면, 한국어 Matrix 소음하 문장인지검사 시 50 혹은 $65 \mathrm{~dB} \mathrm{SPL}$ 에서 소음 혹은 문장을 제시한 경우 소음하 문장 인지능력이 크게 다르지 않았으나 $80 \mathrm{~dB}$ SPL의 제시 레벨에 서는 제시 방법에 상관없이 $50,65 \mathrm{~dB}$ SPL의 제시 레벨을 사 용하였을 때보다 소음하 문장인지도가 저하되었다. 제시 방 법의 영향은 유의하지 않았으므로 Matrix 문장인지검사 시 주로 소음 레벨을 고정하고 문장 레벨을 변동하지만, 검사의 목적에 따라 소음이 아닌 문장 레벨을 고정하고 소음 레벨을 변동하는 방법을 사용하여도 건청 성인의 소음하 문장인지 도에 큰 영향을 주지 않을 것으로 예상한다. 그러나 본 연구 
에서는 건청인만을 대상으로 하였으므로 연구 제한점을 가 진다. 향후 난청인을 대상으로 제시 레벨과 제시 방법에 따른 후속 검증을 진행하여 기준치를 세우고 난청 정도에 따른 적 절한 검사 절차를 확립하는 것이 필요하겠다.

\section{Acknowledgments}

This work was supported by the Ministry of Education of the Republic of Korea and the National Research Foundation of Korea (NRF-2019S1A5A2A01051014).

\section{Author Contribution}

Conceptualization: Kyung Hyun Kim, Jae Hee Lee. Data curation: Kyung Hyun Kim. Formal analysis: Kyung Hyun Kim. Funding acquisition: Jae Hee Lee. Writing - original draft: Kyung Hyun Kim, Jae Hee Lee. Writing — review \& editing: Jae Hee Lee.

\section{ORCIDs}

Jae Hee Lee

https://orcid.org/0000-0002-4152-6434

Kyung Hyun Kim

\section{REFERENCES}

1) Bronkhorst AW. The cocktail party phenomenon: A review of research on speech intelligibility in multiple-talker conditions. Acta Acust United Acust 2000;86(1):117-28.

2) Wu YH, Stangl E, Chipara O, Hasan SS, Welhaven A, Oleson J. Characteristics of real-world signal to noise ratios and speech listening situations of older adults with mild to moderate hearing loss. Ear Hear 2018;39(2):293-304.

3) Hwang JS, Kim KH, Lee JH. Factors affecting sentence-in-noise recognition for normal hearing listeners and listeners with hearing loss. J Audiol Otol 2017;21(2):81-7.

4) Crandell CC. Individual differences in speech recognition ability: Implications for hearing aid selection. Ear Hear 1991;12(6 Suppl): 100S-8S.

5) Wardenga N, Batsoulis C, Wagener KC, Brand T, Lenarz T, Maier H. Do you hear the noise? The German matrix sentence test with a fixed noise level in subjects with normal hearing and hearing impairment. Int J Audiol 2015;54 Suppl 2:71-9.

6) Wilson RH. Clinical experience with the words-in-noise test on 3430 veterans: Comparisons with pure-tone thresholds and word recognition in quiet. J Am Acad Audiol 2011;22(7):405-23.

7) Nilsson M, Soli SD, Sullivan JA. Development of the Hearing in Noise Test for the measurement of speech reception thresholds in quiet and in noise. J Acoust Soc Am 1994;95(2):1085-99.

8) Killion MC, Niquette PA, Gudmundsen GI, Revit LJ, Banerjee S. Development of a quick speech-in-noise test for measuring signalto-noise ratio loss in normal-hearing and hearing-impaired listeners. J Acoust Soc Am 2004;116(4 Pt 1):2395-405.

9) Kollmeier B, Warzybok A, Hochmuth S, Zokoll MA, Uslar V, Brand T, et al. The multilingual matrix test: Principles, applications, and comparison across languages: A review. Int J Audiol 2015;54 Suppl 2:3-16.

10) Lee JH, Yi DW. A comparison of adaptive sentence-in-noise tests. Audiol Speech Res 2017;13(1):9-18.

11) Akeroyd MA, Arlinger S, Bentler RA, Boothroyd A, Dillier N, Dreschler WA, et al. International Collegium of Rehabilitative Audiology (ICRA) recommendations for the construction of multilingual speech tests. ICRA Working Group on multilingual speech tests. Int J Audiol 2015;54 Suppl 2:17-22.

12) Wagener KC, Brand T. Sentence intelligibility in noise for listeners with normal hearing and hearing impairment: Influence of measurement procedure and masking parameters. Int J Audiol 2005;44(3):144-56.

13) Brand T, Hohmann V. Effect of hearing loss, centre frequency, and bandwidth on the shape of loudness functions in categorical loudness scaling. Audiology 2001;40(2):92-103.

14) Kim KH, Lee JH. Evaluation of the Korean Matrix Sentence Test: Verification of the list equivalence and the effect of word position. Audiol Speech Res 2018;14(2):100-7.

15) Brand T, Kollmeier B. Efficient adaptive procedures for threshold and concurrent slope estimates for psychophysics and speech intelligibility tests. J Acoust Soc Am 2002;111(6):2801-10.

16) Green DM. A maximum-likelihood method for estimating thresholds in a yes-no task. J Acoust Soc Am 1993;93(4 Pt 1):2096-105.

17) Lee S, Lee DK. What is the proper way to apply the multiple comparison test? Korean J Anesthesiol 2018;71(5):353-60.

18) Hu H, Xi X, Wong LLN, Hochmuth S, Warzybok A, Kollmeier B. Construction and evaluation of the Mandarin Chinese matrix (CMNmatrix) sentence test for the assessment of speech recognition in noise. Int J Audiol 2018;57(11):838-50.

19) Grant KW, Walden TC. Understanding excessive SNR loss in hearing-impaired listeners. J Am Acad Audiol 2013;24(4):258-73; quiz 337-8.

20) Warzybok A, Zhilinskaya E, Goykhburg M, Tavartkiladze G, Kollmeier B, Boboshko M. Clinical validation of the Russian Matrix test - effect of hearing loss, age, and noise level. Int J Audiol 2020; $1-11$.

21) Warzybok A, Zokoll M, Wardenga N, Ozimek E, Boboshko M, Kollmeier B. Development of the Russian matrix sentence test. Int J Audiol 2015;54 Suppl 2:35-43.

22) Schlueter A, Lemke U, Kollmeier B, Holube I. Normal and timecompressed speech: How does learning affect speech recognition thresholds in noise? Trends Hear 2016;20:1-13.

23) Theunissen M, Swanepoel de W, Hanekom J. Sentence recognition in noise: Variables in compilation and interpretation of tests. Int $\mathrm{J}$ Audiol 2009;48(11):743-57.

24) Molis MR, Summers V. Effects of high presentation levels on recognition of low- and high-frequency speech. ARLO 2003;4(4); 124-8.

25) Summers V, Cord MT. Intelligibility of speech in noise at high presentation levels: Effects of hearing loss and frequency region. J Acoust Soc Am 2007;122(2):1130-7.

26) Studebaker GA, Sherbecoe RL, McDaniel DM, Gwaltney CA. Monosyllabic word recognition at higher-than-normal speech and noise levels. J Acoust Soc Am 1999;105(4):2431-44.

27) Dubno JR, Horwitz AR, Ahlstrom JB. Word recognition in noise at higher-than-normal levels: decreases in scores and increases in masking. J Acoust Soc Am 2005;118(2):914-22.

28) Hornsby BW, Trine TD, Ohde RN. The effects of high presentation levels on consonant feature transmission. J Acoust Soc Am 2005; 118(3 Pt 1):1719-29. 